\title{
The CB1 Cannabinoid Receptor Is the Major Cannabinoid Receptor at Excitatory Presynaptic Sites in the Hippocampus and Cerebellum
}

\author{
Yoshinobu Kawamura, ${ }^{1 *}$ Masahiro Fukaya, ${ }^{2 *}$ Takashi Maejima, ${ }^{3}$ Takayuki Yoshida, ${ }^{1}$ Eriko Miura, ${ }^{2}$ \\ Masahiko Watanabe, ${ }^{2}$ Takako Ohno-Shosaku, ${ }^{4}$ and Masanobu Kano ${ }^{1}$ \\ ${ }^{1}$ Department of Cellular Neuroscience, Graduate School of Medicine, Osaka University, Suita 565-0871, Japan, 2Department of Anatomy, Hokkaido \\ University School of Medicine, Sapporo 060-8638, Japan, ${ }^{3}$ Department of Developmental Physiology, National Institute for Physiological Sciences, Okazaki \\ 444-8585, Japan, and ${ }^{4}$ Department of Impairment Study, Graduate School of Medical Science, Kanazawa University, Kanazawa 920-0942, Japan
}

Endocannabinoids work as retrograde messengers and contribute to short-term and long-term modulation of synaptic transmission via presynaptic cannabinoid receptors. It is generally accepted that the CB1 cannabinoid receptor (CB1) mediates the effects of endocannabinoid in inhibitory synapses. For excitatory synapses, however, contributions of CB1, "CB3," and some other unidentified receptors have been suggested. In the present study we used electrophysiological and immunohistochemical techniques and examined the type(s) of cannabinoid receptor functioning at hippocampal and cerebellar excitatory synapses. Our electrophysiological data clearly demonstrate the predominant contribution of CB1. At hippocampal excitatory synapses on pyramidal neurons the cannabinoid-induced synaptic suppression was reversed by a CB1-specific antagonist, $N$-(piperidin-1-yl)-5-(4-iodophenyl)-1-(2,4-dichlorophenyl)-4-methyl-1Hpyrazole-3-carboxamide (AM251), and was absent in CB1 knock-out mice. At climbing fiber (CF) and parallel fiber (PF) synapses on cerebellar Purkinje cells the cannabinoid-dependent suppression was absent in CB1 knock-out mice. The presence of CB1 at presynaptic terminals was confirmed by immunohistochemical experiments with specific antibodies against CB1. In immunoelectron microscopy the densities of CB1-positive signals in hippocampal excitatory terminals and cerebellar PF terminals were much lower than in inhibitory terminals but were clearly higher than the background. Along the long axis of PFs, the CB1 was localized at a much higher density on the perisynaptic membrane than on the extrasynaptic and synaptic regions. In contrast, CB1 density was low in CF terminals and was not significantly higher than the background. Despite the discrepancy between the electrophysiological and morphological data for CB1 expression on CFs, these results collectively indicate that CB1 is responsible for cannabinoid-dependent suppression of excitatory transmission in the hippocampus and cerebellum.

Key words: cannabinoid; CB1 receptor; presynaptic suppression; excitatory synapse; pyramidal cell; Purkinje cell; hippocampus; cerebellum

\section{Introduction}

Endogenous cannabinoids (endocannabinoids) are released from postsynaptic neurons, act retrogradely onto presynaptic cannabinoid receptors, and cause short-term or long-term suppression of transmitter release (Alger, 2002; Freund et al., 2003; Gerdeman and Lovinger, 2003; Kano et al., 2004; Ohno-Shosaku et al., 2005). So far two types of cannabinoid receptors (CB1 and CB2) have been identified (Matsuda et al., 1990; Munro et al.,

Received Nov. 12, 2005; revised Feb. 4, 2006; accepted Feb. 4, 2006.

This work was supported in part by Grants-in-Aid for Scientific Research (17023021 and 17100004 to M.K.; 15300133 and 17024021 to T. 0.-S.; 17023001 to M.W.) and Special Coordination Funds for Promoting Science and Technology (M.K.) from the Ministry of Education, Culture, Sports, Science, and Technology of Japan. We thank A. Zimmer for providing the original breeding pairs of $\mathrm{CB} 1$ knock-out mice, and T. Miyazaki and M. Uchigashima for the production of CB1 antibodies.

*Y.K. and M.F. contributed equally to this work.

Correspondence should be addressed to Masanobu Kano, Department of Cellular Neuroscience, Graduate School of Medicine, Osaka University, Suita 565-0871, Japan. E-mail: mkano@cns.med.osaka-u.ac.jp. DOI:10.1523/JNEUROSCI.4872-05.2006

Copyright $\odot 2006$ Society for Neuroscience $\quad$ 0270-6474/06/262991-11\$15.00/0
1993). The CB1 is expressed predominantly in the nervous system, whereas the CB2 is present in the immune system (Howlett et al., 2002). Recent studies on CB1 and CB2 knock-out mice have suggested the existence of non-CB1, non-CB2 cannabinoid receptors in the brain (Hajos and Freund, 2002b; Wiley and Martin, 2002; Begg et al., 2005).

It is now well established that CB1 is the major presynaptic cannabinoid receptor at subsets of inhibitory synapses. Immunocytochemical (Katona et al., 1999, 2001; Egertova and Elphick, 2000; Hajos et al., 2000; Bodor et al., 2005), biochemical (Kofalvi et al., 2005), and electrophysiological (Hajos et al., 2001; Varma et al., 2001; Wilson et al., 2001; Yoshida et al., 2002) studies on CB1 knock-out mice consistently support this notion. For excitatory synapses, however, the type(s) of cannabinoid receptors are still controversial. Contributions of CB1 (Gerdeman et al., 2002; Ohno-Shosaku et al., 2002b; Robbe et al., 2002; Melis et al., 2004), "CB3" (Hajos et al., 2001; Hajos and Freund, 2002a), and non-CB1, non-CB3 cannabinoid receptors (Kofalvi et al., 2003, 2005) have been reported, raising a possibility that presynaptic 
cannabinoid receptors may be heterogeneous at excitatory synapses, depending on brain regions and/or developmental stages. For hippocampal excitatory synapses contradictory results have been reported from electrophysiological studies that used CB1 knock-out mice. Some demonstrate the predominance of CB1 (Ohno-Shosaku et al., 2002b; Straiker and Mackie, 2005), and others show the contribution of CB3 (Hajos et al., 2001; Hajos and Freund, 2002a). In addition, Hoffman et al. (2005) reported electrophysiologically that there might be species and strain differences in the type(s) of cannabinoid receptor at hippocampal excitatory synaptic terminals (Hoffman et al., 2005). Immunocytochemical studies have failed to detect CB1-positive signals on excitatory presynaptic sites in the hippocampus, supporting the CB3 hypothesis.

In the present study we evaluated the type(s) of cannabinoid receptors functioning at excitatory synapses in the hippocampus and cerebellum. Our electrophysiological experiments on CB1 knock-out mice clearly demonstrated the predominance of CB1 for cannabinoid-dependent synaptic modulation at hippocampal excitatory synapses and cerebellar parallel fiber (PF) and climbing fiber (CF) excitatory synapses onto Purkinje cells (PCs). Our data supported neither involvement of CB3 nor developmental change in cannabinoid receptor type. Our immunohistochemical analyses using specific antibodies against CB1 have demonstrated significant expression of $\mathrm{CB} 1$ on excitatory terminals in the hippocampus and cerebellum, yet CB1 expression on CFs was not significantly higher than the background. Although a discrepancy between the electrophysiological and morphological data remains for CB1 expression on CFs, the present results collectively indicate that the $\mathrm{CB} 1$ is the major cannabinoid receptor responsible for synaptic modulation at excitatory synapses in the hippocampus and cerebellum.

\section{Materials and Methods}

All experiments were performed according to the guidelines laid down by the animal welfare committees of Kanazawa University, Hokkaido University, and the United States National Institutes of Health Guide for the Care and Use of Laboratory Animals.

Electrophysiology with hippocampal slices. C57BL/6 mice (10 d to 3 months old; The Jackson Laboratory, Bar Harbor, ME, or Charles River Laboratories, Boston, MA) or Wistar rats (21-28 d old; from Japan SLC, Shizuoka, Japan) were anesthetized deeply with halothane and decapitated. Transverse slices were prepared from the hippocampus as described previously (Tsubokawa et al., 2000; Ohno-Shosaku et al., 2002a,b; Hashimotodani et al., 2005). For the recording of EPSCs a single slice was transferred to a submerged chamber mounted on the stage of an upright microscope (Axioskop, Zeiss, Oberkochen, Germany). The slice was perfused continuously with an external solution at $30-32^{\circ} \mathrm{C}$ that was composed of the following (in mM): $125 \mathrm{NaCl}, 2.5 \mathrm{KCl}, 2 \mathrm{CaCl}_{2}, 2 \mathrm{MgCl}_{2}$, $1.25 \mathrm{NaH}_{2} \mathrm{PO}_{4}, 26 \mathrm{NaHCO}_{3}$, and 20 glucose, bubbled with a mixture of $95 \% \mathrm{O}_{2} / 5 \% \mathrm{CO}_{2}$, with a final $\mathrm{pH}$ of 7.4 . Bicuculline methiodide $(10 \mu \mathrm{M})$ was added to the solution during whole-cell recordings to block inhibitory GABAergic currents. Whole-cell recordings were made from the somata of visually identified CA1 pyramidal cells, using patch pipettes (3-5 $\mathrm{M} \Omega$ resistance) filled with a solution containing the following (in mM): $130 \mathrm{~K}$-gluconate, $10 \mathrm{KCl}, 10 \mathrm{NaCl}, 0.5 \mathrm{EGTA}, 10 \mathrm{HEPES}, 4.6 \mathrm{Mg}$ ATP, and 0.4 GTP (pH-adjusted to 7.3 with $\mathrm{KOH}$; osmolarity, 290-300 $\mathrm{mOsm}$ ). Capacitance was compensated fully by a patch-clamp amplifier (EPC10; HEKA Electronics, Lambrecht/Pfalz, Germany). The range of series resistance we accepted for recordings was $8-25 \mathrm{M} \Omega$. The membrane potential was held at $-70 \mathrm{mV}$. Bipolar stimulation electrodes constructed from thin tungsten wire were placed on the stratum radiatum to generate EPSCs. EPSCs were evoked by delivering a short current pulse of $0.1 \mathrm{~ms}$ duration. Test stimulations were delivered every $5 \mathrm{~s}$. The signals were filtered at $3 \mathrm{kHz}$ and digitized at $20 \mathrm{kHz}$. On-line data acquisition and off-line data analysis were performed by using PULSE software
(HEKA Electronics). $R$-(+)-(2,3-dihydro-5-methyl-3-[(4-morpholinyl) methyl]pyrol[1,2,3-de]-1,4-benzoxazin-6-yl)(1-naphthalenyl) methanone mesylate (WIN55,212-2), N-(piperidin-1-yl)-5-(4-iodophenyl)1-(2,4-dichlorophenyl)-4-methyl-1H-pyrazole-3-carboxamide (AM251), and bicuculline methiodide were purchased from Tocris Cookson (Ballwin, MO). N-piperidino-5-(4-chlorophenyl)-1-(2,4dichlorophenyl)-4-methyl-3-pyrazole-carboxamide (SR141716A) was a generous gift from Sanofi Research (Libourne, France). For the perfusion of solutions containing WIN55,212-2 or AM251, different tubes were used to avoid contamination.

Electrophysiology with cerebellar slices. C57BL/6 mice (9-14 d old) were anesthetized deeply with halothane and decapitated. Parasagittal slices (250 $\mu \mathrm{m}$ thick) were cut from the cerebellar vermis as described previously (Kano et al., 1995; Maejima et al., 2001, 2005). Slices were perfused with the external solution at $30^{\circ} \mathrm{C}$ containing the following (in mM): 125 $\mathrm{NaCl}, 2.5 \mathrm{KCl}, 2 \mathrm{CaCl}_{2}, 1 \mathrm{MgSO}_{4}, 1.25 \mathrm{NaH}_{2} \mathrm{PO}_{4}, 26 \mathrm{NaHCO}_{3}, 20$ glucose, and 0.01 bicuculline, bubbled with $95 \% \mathrm{O}_{2} / 5 \% \mathrm{CO}_{2}$. Whole-cell recordings were made from $\mathrm{PC}$ somata. Patch pipettes (2-4 M $\Omega$ ) were filled with a solution containing the following (in mM): $60 \mathrm{CsCl}, 10 \mathrm{Cs}$ D-gluconate, 20 TEA-Cl, 30 HEPES, $4 \mathrm{MgCl}_{2}$, 20 BAPTA, $4 \mathrm{Mg}$-ATP, and $0.4 \mathrm{Na}-\mathrm{GTP}$ (pH 7.3-adjusted with $\mathrm{CsOH}$ ). In the experiments for the depolarization-induced suppression of EPSCs the following pipette solution was used (in mM): $140 \mathrm{CsCl}, 10 \mathrm{HEPES}, 0.1 \mathrm{CaCl}_{2}, 4.6 \mathrm{MgCl}_{2}, 1$ EGTA, $4 \mathrm{Na}-\mathrm{ATP}$, and $0.4 \mathrm{Na}-\mathrm{GTP}, \mathrm{pH}$ 7.3. The pipette access resistance was compensated by $70-80 \%$. A glass electrode filled with the external solution was placed in the granule cell layer or the molecular layer to stimulate CFs or PFs, respectively. For the recording of CF-EPSCs the membrane potential was set at -20 or $-10 \mathrm{mV}$ to reduce their amplitudes and inactivate voltage-dependent conductance. In the experiments for the depolarization-induced suppression of CF-EPSCs the recordings were made at a holding potential of $-70 \mathrm{mV}$ so as not to inactivate voltage-gated $\mathrm{Ca}^{2+}$ conductance, and CF-EPSC amplitudes were reduced by adding CNQX $(1-2 \mu \mathrm{M})$. For the recording of PF-EPSCs the membrane potential was set at $-70 \mathrm{mV}$.

CB1 knock-out mice. Breeding pairs of CB1 knock-out mice that have been backcrossed to the C57BL/6 strain were kindly provided by A. Zimmer (Department of Molecular Neurobiology, University of Bonn, Bonn, Germany) (Zimmer et al., 1999). Homozygous mutant mice were produced with heterozygous intermatings. The mouse genotypes were checked by conventional PCR technique on tail biopsies. For experiments the mutant mice and their wild-type littermates or wild-type C57BL/6 mice in both sexes were used. Animals were housed in groups under standard laboratory conditions ( $12 \mathrm{~h}$ light/dark cycle) with food and water available ad libitum.

Antibodies. We used polyclonal antibodies raised in the rabbit, guinea pig, or goat: CB1 [rabbit and guinea pig antibodies, C-terminal 31 amino acids (443-473) of mouse CB1 (Fukudome et al., 2004)], vesicular glutamate transporter type 1 [VGluT1; rabbit, guinea pig, and goat, C-30 (531-560 of rat VGluT1), NM020309], VGluT2 [guinea pig and goat, C-34 (550-582 of mouse VGluT2), BC038375], vesicular GABA transporter [VGAT; rabbit, guinea pig, and goat, N-82 (31-112 of mouse VGAT), BC052020], and glutamate/aspartate transporter [GLAST; rabbit, guinea pig, and goat, C-41 (503-543 of mouse GLAST), AF330257]. Antibodies to VGluT1, VGluT2, VGAT, and GLAST were produced and affinity-purified, and their specificity was confirmed by immunoblot and immunohistochemical patterns, which were identical to our previous reports (Shibata et al., 1997; Miyazaki et al., 2003). We also used rabbit antiserum to human recombinant calretinin (number 7699/4, Swant, Bellinzona, Switzerland). All of these antibodies were used at $1 \mu \mathrm{g} / \mathrm{ml}$ for affinity-purified antibodies or 1:1000 for calretinin antiserum, unless otherwise noted.

Immunofluorescence. Under pentobarbital anesthesia $(100 \mathrm{mg} / \mathrm{kg}$ of body weight, i.p.) C57BL/6 mice and CB1 knock-out mice were perfused transcardially with $4 \%$ paraformaldehyde in $0.1 \mathrm{~m}$ sodium phosphate buffer (PB), $\mathrm{pH}$ 7.2. After additional immersion in the same fixative for $4 \mathrm{~h}$ the sections (50 $\mu \mathrm{m}$ in thickness) were prepared with a microslicer (VT1000S, Leica, Nussloch, Germany). All incubations were done at room temperature, and PBS containing $0.1 \%$ Tween 20 was used as an antibody diluent and washing solution. After blocking with $10 \%$ normal 
donkey serum for $20 \mathrm{~min}$ the sections were subjected to double or triple immunofluorescence. Sections were incubated overnight in a mixture of primary antibodies raised in different species. After being washed, the sections were incubated for $2 \mathrm{~h}$ in a mixture of 1:200 diluted speciesspecific secondary antibodies linked to Alexa 488 (Molecular Probes, Eugene, OR), indocarbocyanine (Cy3), and indodicarbocyanine (Cy5) (Jackson ImmunoResearch, West Grove, PA). Images of single optical sections were taken with a confocal laser-scanning microscope (FV1000, Olympus, Tokyo, Japan). All images were obtained by restricting the width of emission wavelength, using spectral slit, and by adopting the sequential mode of laser scanning, both to minimize the fluorescence cross talk. To also avoid bias from the choice of primary and secondary antibodies in terms of species, we checked two different combinations of primary antibodies for a given multiple labeling, e.g., rabbit CB1/guinea pig VGluT1/goat VGAT antibodies and guinea pig CB1/goat VGluT1/ rabbit VGAT antibodies.

Immunoelectron microscopy. For preembedding with silver-intensified immunogold, C57BL/6 mice and CB1 knock-out mice were perfused transcardially with $4 \%$ paraformaldehyde $/ 0.1 \%$ glutaraldehyde in $0.1 \mathrm{M}$ PB under deep pentobarbital anesthesia. After being blocked with 5\% BSA in TBS $/ 0.02 \%$ saponin (blocking solution), microslicer sections were incubated overnight with rabbit CB1 antibody and then with antirabbit IgG conjugated to $1.4 \mathrm{~nm}$ gold particles (Nanoprobes, Stony Brook, NY), both being diluted with blocking solution. After silver enhancement (HQ Silver, Nanoprobes) the sections were osmificated, dehydrated, and embedded in Epon 812 resin. Ultrathin sections were prepared from $<1.5 \mu \mathrm{m}$ from the section surface with an ultramicrotome (Leica Ultracut UCT, Leica) and were stained with $2 \%$ uranyl acetate. For quantitative analyses the number of silver particles per $1 \mu \mathrm{m}$ of plasma membrane was calculated by using IPLab software (Nippon Roper, Tokyo, Japan).

Statistics. Averaged data from different experiments are presented as the mean \pm SEM. Statistical significance was assessed by Student's $t$ test. One, two, and three asterisks indicate $p<0.05, p<0.01$, and $p<0.001$, respectively.

\section{Results}

\section{CB1-dependent suppression at hippocampal excitatory synapses}

First we examined whether the CB1 contributes to the cannabinoid-induced suppression of excitatory synaptic transmission in hippocampal slices prepared from juvenile C57BL/6 mice (10-19 d old; The Jackson Laboratory) similar in age to the cultured hippocampal neurons that were used previously (OhnoShosaku et al., 2002b; Hashimotodani et al., 2005). Bath application of a cannabinoid agonist, WIN55,212-2 (2 $\mu \mathrm{M})$, decreased the amplitude of EPSCs recorded from CA1 pyramidal neurons (Fig. $1 A, B$ ). This suppression was accompanied by an increase in the paired pulse ratio (Fig. $1 C, D$ ), indicating that its locus of action is presynaptic. Then we applied a CB1-specific antagonist, AM251, which is reported to antagonize CB1, but not CB3 (Hajos and Freund, 2002a). AM251 $(2 \mu \mathrm{M})$ reversed the effects of WIN55,212-2 on EPSC amplitude and paired pulse ratio (Fig. $1 A, B, D)$. AM251 application alone in the absence of WIN55,212-2 had no effect on EPSC amplitude (90.53 $\pm 7.23 \%$; $n=6$ ) (data not shown). Furthermore, we found that the WIN55,212-2-induced suppression was almost absent in CB1 knock-out mice (Fig. $1 E, F$ ). The remaining slight reduction of EPSC amplitude by WIN55,212-2 (2 $\mu \mathrm{M})$ in CB1 knock-out mice (Fig. $1 F$ ) was not reversed by the subsequent addition of AM251 $(2 \mu \mathrm{M})$ (Fig. $1 F)$. In addition, SR141716A (2 $\mu \mathrm{M})$, which is reported to antagonize both CB1 and CB3 (Hajos et al., 2001), also had no effect on the slight reduction of EPSC amplitude (Fig. $1 F$ ). These results indicate that $\mathrm{CB} 1$ is the major cannabinoid receptor mediating cannabinoid-induced presynaptic suppression of ex-
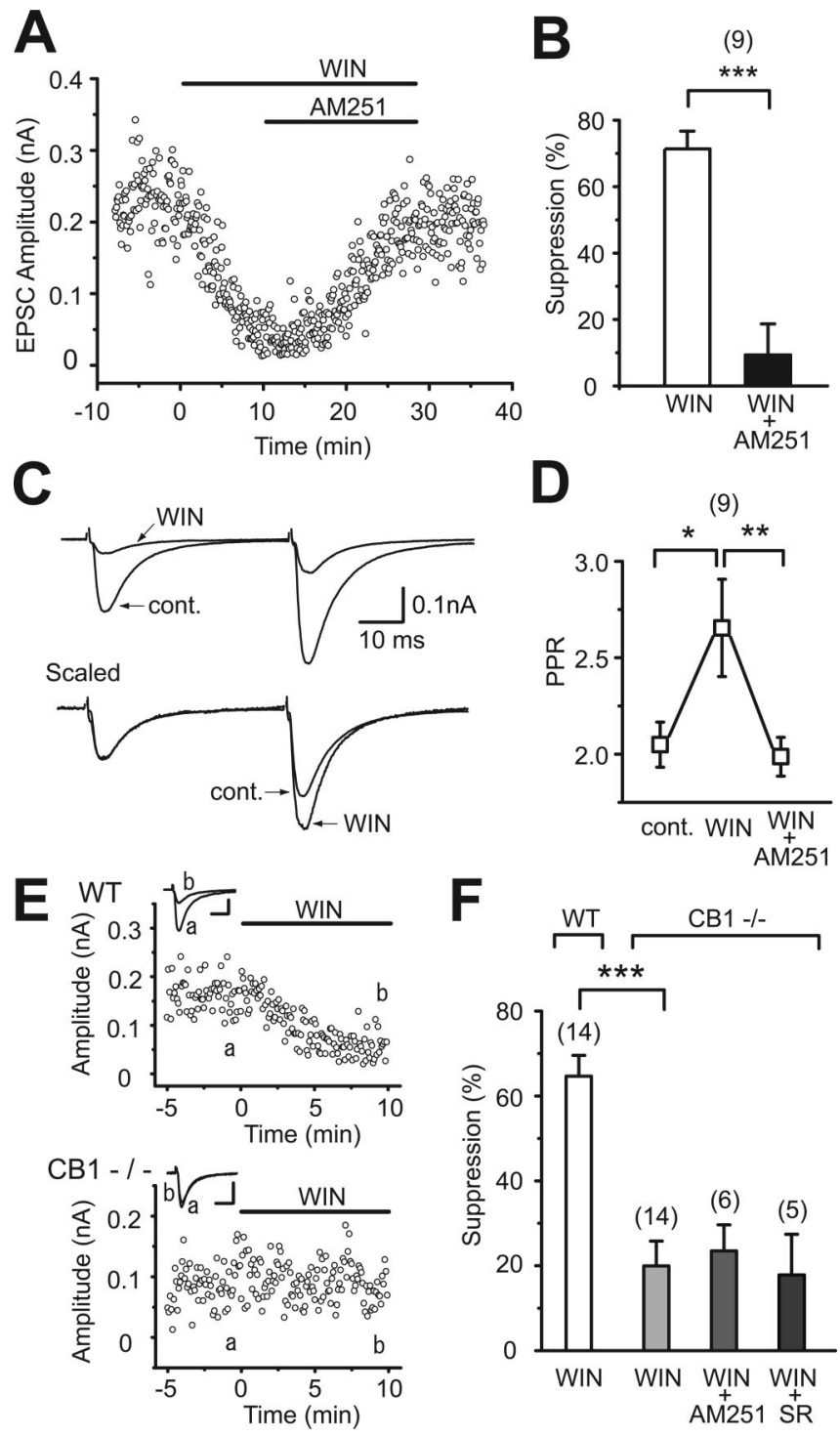

Figure 1. CB1 dependence of cannabinoid-induced suppression of excitatory transmission in hippocampal slices of young mice. $\boldsymbol{A}$, Representative results showing WIN55,212-2-induced $(2 \mu \mathrm{M})$ suppression of EPSCs and its reversal by AM251 $(2 \mu \mathrm{M})$. $\boldsymbol{B}$, Averaged data for percentage suppression of EPSC amplitudes by WIN55,212-2 (2 $\mu \mathrm{M})$ and WIN55,212-2 (2 $\mu \mathrm{M})$ plus AM251 (2 $\mu \mathrm{M})$. C, Sample traces of EPSC evoked by paired stimuli (50 ms interval) before (cont.) and during the application of WIN55,212-2 (2 $\mu \mathrm{m})$. Traces scaled to the amplitude of the first EPSC are shown at the bottom. Each trace is the average of 24 consecutive EPSCS. D, Averaged data for the paired pulse ratio of EPSCS obtained before (cont.) and during the application of WIN55,212-2 (2 $\mu \mathrm{M})$ and after the additional application of AM251 $(2 \mu \mathrm{M})$. $\boldsymbol{E}$, Representative results showing effects of WIN55,212-2 (2 $\mu \mathrm{m})$ on EPSCs in wild-type (WT) and CB1 knock-out $\left(C B 1^{-1-}\right)$ mice. Sample EPSC traces $(a, b)$ were obtained at the time points indicated in the graphs. Calibration: 50 pA, 10 ms. $\boldsymbol{F}$, Summary bar graph for percentage suppression of EPSC amplitudes by WIN55,212-2 (2 $\mu \mathrm{M})$ in wild-type mice (WT) and by WIN55,212-2 (2 $\mu \mathrm{M})$, WIN55,212-2 (2 $\mu \mathrm{M})$ plus AM251 (2 $\mu \mathrm{M})$, and WIN55,212-2 (2 $\mu \mathrm{M})$ plus SR141716A (2 $\mu \mathrm{M})$ in CB1 knock-out mice ( $\left(B 1^{-1-}\right)$. The numbers of tested cells are indicated in parentheses in $B, D$, and $\boldsymbol{F}$. Error bars indicate the mean \pm SEM; ${ }^{*} p<0.05,{ }^{* *} p<0.01$, and ${ }^{* * *} p<0.001$.

citatory transmission in hippocampal slices from juvenile C57BL/6 mice.

Next we examined the possibility that the nature of presynaptic cannabinoid receptors might change during development. We examined the effects of cannabinoids in young adult (27-39 d old) and adult ( $>12$ weeks old) C57BL/6 mice. In young adult wild-type mice, WIN55,212-2 decreased EPSC amplitude, and this effect was reversed by AM251 (Fig. 2A,C, WT). In CB1 
knock-out mice of the same age, WIN55,212-2 had no effect (Fig. 2B,C, $\left.\mathrm{CB} 1^{-1-}\right)$. We confirmed that a higher concentration of WIN55,212-2 (5 $\mu \mathrm{M})$ caused no suppression in CB1 knock-out mice $(105.3 \pm 10.08 \% ; n=3)$ (data not shown). Similar CB1 dependence was observed in adult mice. WIN55,212-2 markedly suppressed EPSCs in wild-type mice, but not in CB1 knock-out mice (Fig. 2D$F)$. These results clearly indicate that $\mathrm{CB} 1$ is the major cannabinoid receptor at excitatory synaptic terminals of the C57BL/6 mouse hippocampus regardless of age.

To exclude the possibility that the CB1 predominance described above is unique to the mouse, we used hippocampal slices from Wistar rats and examined the effects of cannabinoids. We found that WIN55,212-2 suppressed EPSCs recorded from rat CA1 pyramidal neurons (Fig. $3 A, B)$ and increased the paired pulse ratio (Fig. 3C,D). These effects were reversed completely by AM251 (Fig. 3), as observed in mouse hippocampal slices. These results indicate that the CB1 predominance at excitatory presynaptic sites in the hippocampus is common for mice and rats.

\section{CB1-dependent suppression at}

\section{cerebellar excitatory synapses}

We also determined the type of presynaptic cannabinoid receptor functioning at excitatory CF and PF synapses on PCs in the cerebellum. CFs originate from the contralateral inferior olive and form strong excitatory synapses onto proximal dendrites, whereas PFs are axons of granule cells and form en passant synapses on distal dendrites (Ito, 1984). As we have reported previously, CF-mediated EPSCs (CF-EPSCs) were suppressed by WIN55,212-2 (Fig. 4A), the group I metabotropic glutamate receptor (I-mGluR) agonist dihydrophenylglycine (DHPG) (Fig. $4 C$, WT), and postsynaptic depolarization (Fig. 4D, WT). The depressant effects of DHPG and depolarization are known to be mediated by endocannabinoids that are released from postsynaptic PCs (Maejima et al., 2001). These three forms of suppression were totally absent in CB1 knock-out mice (Fig. $4 B-D$, $\left.\mathrm{CB}^{-1-}\right)$. Furthermore, we obtained similar results for $\mathrm{PF} \rightarrow \mathrm{PC}$ synapses. PF-mediated EPSCs (PF-EPSCs) were suppressed by WIN55,212-2, DHPG, and depolarization in wild-type mice, but not in CB1 knock-out mice (Fig. $4 E, F$ ). These results indicate that $\mathrm{CB} 1$ is the major cannabinoid receptor that mediates the effects of exogenous and endogenous cannabinoids at excitatory $\mathrm{CF}$ and PF synapses onto cerebellar PCs.

\section{Immunohistochemistry of CB1}

We then examined the immunohistochemical distribution of CB1 in the hippocampus (see Figs. 5, 6) and the cerebellar cortex (see Figs. 7-9). In both regions intense staining was detected in a fibrous pattern in the neuropil and on the neuronal surface, whereas staining was almost vacant inside neuronal cell bodies. The specificity of these signals was confirmed by their virtual disappearance in the CB1 knock-out brain, as shown in our previous (Fukudome et al., 2004) and present studies.
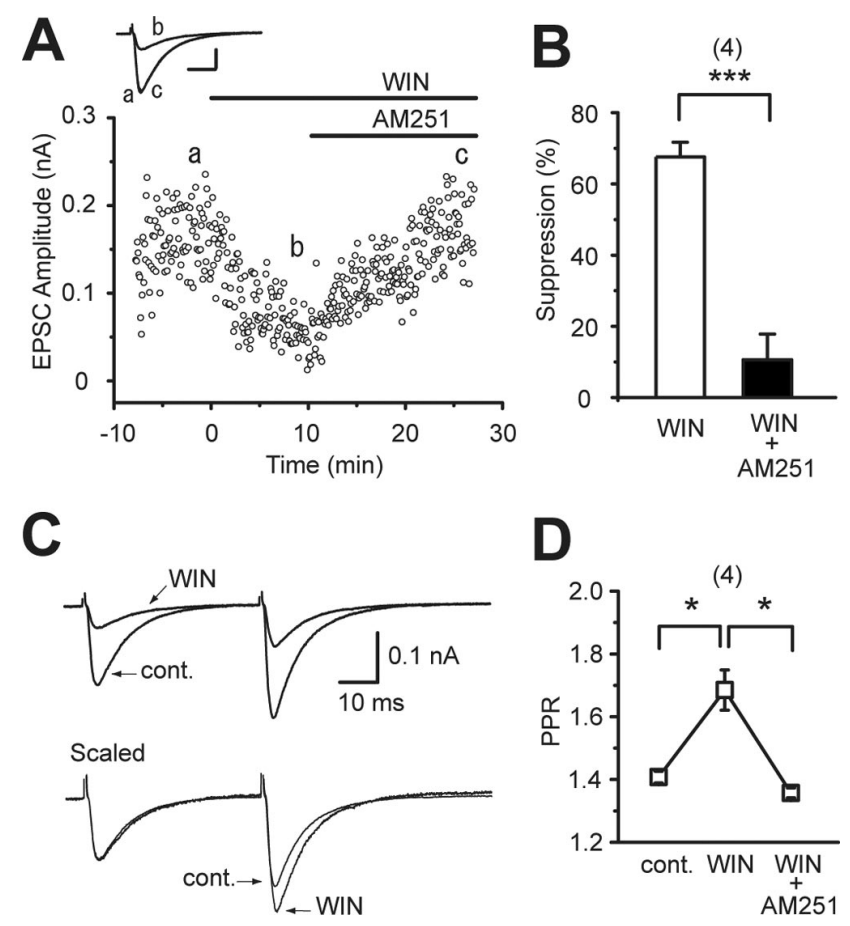

Figure 3. Reversal of cannabinoid-induced suppression of EPSCs by AM251 in rat hippocampal slices. A, Representative case showing WIN55,212-2-induced ( $2 \mu \mathrm{m})$ suppression of EPSCS and its reversal by AM251 ( $2 \mu \mathrm{m})$. EPSC traces (a-c) acquired at the time points indicated in the graph are superimposed (top). Calibration: $50 \mathrm{pA}, 10 \mathrm{~ms}$. $\boldsymbol{B}$, Summary bar graph for percentage suppression of EPSC amplitudes by WIN55,212-2 (2 $\mu \mathrm{M})$ and WIN55,212-2 (2 $\mu \mathrm{M})$ plus AM251 $(2 \mu \mathrm{M})$. C, Sample traces of EPSCs evoked by paired stimuli before (cont.) and during the application of WIN55,212-2 (2 $\mu \mathrm{m}$ ). D, Averaged data for paired pulse ratio of EPSCs obtained under the indicated conditions. The number of tested cells are indicated in parentheses in $\boldsymbol{B}$ and $\boldsymbol{D}$. Error bars indicate the mean \pm SEM; ${ }^{*} p<0.05$ and ${ }^{* * *} p<0.001$. 


\section{CF-EPSC}
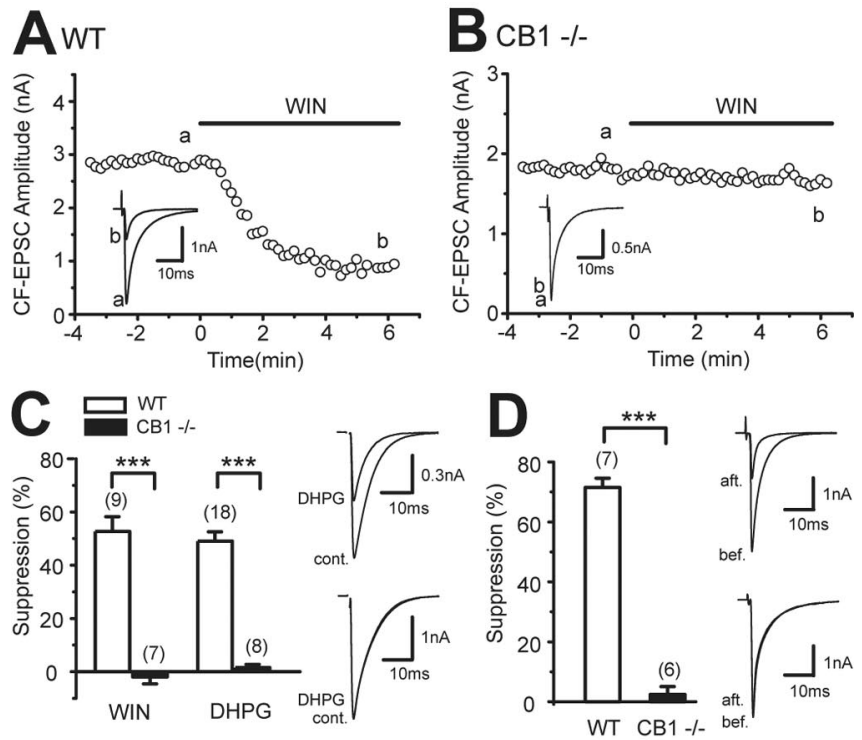

\section{PF-EPSC}
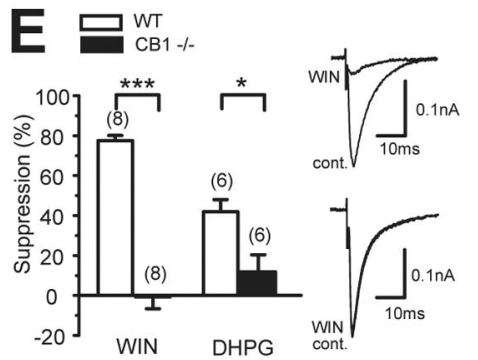

$\mathbf{F}$

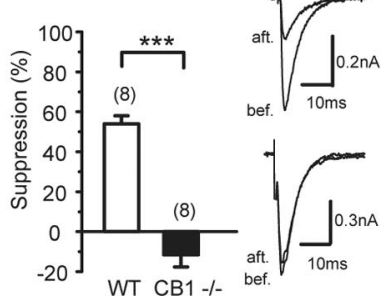

Figure 4. CB1 dependence of cannabinoid-induced suppression of CF and PF inputs to cerebellar PCS. $\boldsymbol{A}, \boldsymbol{B}$, Representative results showing effects of WIN55,212-2 (5 $\mu \mathrm{M})$ on CF-EPSCs in wild-type (WT, $\boldsymbol{A})$ and $\mathrm{CB} 1$ knock-out $\left(\mathrm{CB} 1^{-1-}, \boldsymbol{B}\right)$ mice. Sample EPSC traces $(\mathrm{a}, \mathrm{b})$ were obtained at the time points indicated in the graphs. Each trace is an average of six consecutive EPSCS. C, Summary bar graph showing the effects of WIN55,212-2 (5 $\mu \mathrm{m})$ and DHPG (50 $\mu \mathrm{m})$ on CF-EPSCs in wild-type and CB1 knock-out mice. CF-EPSC traces obtained before (cont.) and during the application of DHPG are superimposed (right). D, Averaged data for depolarizationinduced suppression of CF-EPSCs in each genotype. The suppression was induced by five short voltage steps ( $100 \mathrm{~ms} ; 0 \mathrm{mV}, 1 \mathrm{~Hz}$ ). (F-EPSC traces obtained $5 \mathrm{~s}$ before (bef.) and $5 \mathrm{~s}$ after (aft.) depolarization are superimposed (right). $\boldsymbol{E}$, Summary bar graph showing the effects of WIN55,212-2 (5 $\mu \mathrm{m})$ and DHPG $(50 \mu \mathrm{m})$ on PF-EPSCs in wild-type and CB1 knock-out mice. PF-EPSC traces obtained before (cont.) and during the application of WIN55,212-2 (WIN) are superimposed (right). F, Averaged data for depolarization-induced suppression of PF-EPSCs in each genotype. PF-EPSC traces obtained $5 \mathrm{~s}$ before (bef.) and $5 \mathrm{~s}$ after (aft.) depolarization are superimposed (right). The numbers of tested cells are indicated in parentheses in $\boldsymbol{C}-\boldsymbol{F}$. Error bars indicate the mean \pm SEM; ${ }^{*} p<0.05$ and ${ }^{* * *} p<0.001$.

\section{CB1 localization in the hippocampus}

In the adult hippocampus intense signals for CB1 were observed as short woven fibers distributed in each layer of Ammon's horn and dentate gyrus (Fig. 5A-F, red). CB1-labeled fibers often were overlapped with signals for VGAT or were connected to VGATpositive inhibitory terminals (Fig. $5 B_{1}, D_{1}, F_{1}$, yellow). CB1 also was detected in the innermost zone of the dentate gyrus molecular layer (Fig. $5 E$ ) in which large intense labeling was overlapped with or continuous to the VGAT signal (Fig. $5 F_{1}$, yellow). In contrast, small labeling with low intensity was overlapped with the signal for VGluT1 (Fig. $5 F_{2}$, purple). The small weak labeling, but not the large intense one, also was immunostained for calreti$\operatorname{nin}$ (Fig. 5G,H, white), a marker for mossy cells that project ex- citatory axons to the basal region of granule cell dendrites (Matyas et al., 2004). No overlap or association of CB1 and VGluT1 was discerned in other hippocampal regions with the CB1 antibody concentration of $1 \mu \mathrm{g} / \mathrm{ml}$ (Fig. $5 B_{2}, D_{2}$ ), which we usually use for immunofluorescence with affinity-purified antibodies. However, when we raised the concentration to 3 and $10 \mu \mathrm{g} / \mathrm{ml}$, faint tiny signals came up in the neuropil among strongly CB1positive inhibitory fibers where VGluT1-positive terminals were densely distributed (Fig. $5 I, J$ ). The signals were judged to be specific to $\mathrm{CB} 1$, because such signals were absent in CB1 knockout mice (Fig. $5 \mathrm{~K}$ ).

We then examined the precise subcellular localization of CB1 in the stratum radiatum of the CA1 region and in the innermost zone of the dentate gyrus molecular layer by using silverenhanced immunogold electron microscopy (Fig. 6). The heaviest labeling was detected in inhibitory axons and terminals that formed symmetrical synapses with dendritic shafts (Fig. $6 A, B, D)$. Much lower labeling also was detected around excitatory terminals forming asymmetrical synapses with dendritic spines (Fig. 6C,D). Most of the CB1 labeling was seen along the cell membrane. To quantify the intensity of CB1 labeling, we calculated the labeling density as the number of metal particles per micrometer of the cell membrane, using randomly taken synaptic profiles. The labeling density in inhibitory terminals was $\sim 20$ times higher than in excitatory terminals in the CA1 stratum radiatum (Fig. $6 G$ ) and was $\sim 10$ times higher in the dentate gyrus molecular layer (Fig. $6 H$ ). The density in excitatory terminals was clearly higher than the background level, which was estimated in shaft dendrites of pyramidal cells or granule cells taken from the same sections (Fig. 6G,H). Furthermore, the density in excitatory terminals in adult was higher than the noise level, which was estimated from immunogold particle density in excitatory terminals of CB1 knock-out mice (Fig. 6G). It should be noted that the junctional terminal membrane of any synapse type as well as the dendritic and spine membrane of pyramidal and granule cells was hardly labeled. We obtained essentially the same results in the CA1 region at postnatal day 14 (P14) (Fig. 6E,F,I), suggesting that there is no developmental alteration in CB1 distribution. These results clearly demonstrate that CB1 is present in both inhibitory and excitatory presynaptic sites in the hippocampus, but the density is $\sim 10-20$ times higher in inhibitory synapses than in excitatory ones.

\section{CB1 localization in the cerebellar cortex}

The distribution of CB1 was examined in the cerebellar cortex at P14 (Fig. $7 A-E$ ) and adult (Fig. $7 F-J$ ). At P14 the CB1 labeling was very intense in the molecular layer, showing a superficial-todeep gradient (Fig. 7A). At low magnification CB1 staining was pseudo-overlapped with the labeling of VGluT1, a marker for PF terminals (Fig. 7A). At high magnification CB1- and VGluT1labeled structures both were seen as tiny puncta densely distributed in the neuropil; they were mutually exclusive and positioned side by side (Fig. 7B). VGluT2 is known to be expressed in both $\mathrm{CF}$ and immature PF terminals in the developing cerebellum (Miyazaki et al., 2003). Similar to the distribution of VGluT1 (Fig. 7B), VGluT2-labeled PF terminals were pseudo-overlapped with CB1 signals at low magnification (Fig. $7 C$ ), but the two immunofluorescent structures were clearly distinct at higher magnification (Fig. 7D $)$. VGluT2-labeled CF terminals could be distinguished from PF terminals by their much larger size and clear association with dendritic shafts $\left(\right.$ Fig. $\left.7 D_{1}\right)$. CB1 was neither detected within CF terminals nor associated with them (Fig. 7D). CB1 labeling was also absent within and around CF terminals, 
even when the concentration of CB1 antibody was raised to $10 \mu \mathrm{g} / \mathrm{ml}$ (data not shown). CB1 labeling was not overlapped with the staining of GLAST, a marker of Bergmann glia (Fig. 7E). The only structures identified to carry $\mathrm{CB} 1$ at the light microscopic level were VGAT-positive structures. CB1 was overlapped with VGAT along inhibitory fibers and terminals around PC somata (Fig. $7 C$, purple) and also around inhibitory terminals in contact with PC dendrites (Fig. 7D).

These immunofluorescence patterns at P14 were essentially similar to those in the adult cerebellum (Fig. 7F-J). Differences are the loss of CB1 gradient in the molecular layer (Fig. $7 F, H$ ), disappearance of VGluT2 labeling from PF terminals (Fig. $7 H, I)$, and appearance of very intense labeling for $\mathrm{CB} 1$ in the pinceau formation (Fig. $7 F, H$, asterisks) that consists of clustered basket cell axons and terminals surrounding the base of PC somata and axon initial segments.

We used silver-enhanced immunogold for parasagittal cerebellar sections to examine CB1 localization in PC synapses at P14 and adult (Fig. 8). Heavy labeling was detected at both stages in the inhibitory terminals forming symmetrical synapses with dendritic shafts of PCs (Fig. 8A,D). Moreover, moderate labeling was seen in the PF terminals forming asymmetrical synapses with dendritic spines of PCs (Fig. $8 B, E)$. As to CF synapses, weak labeling was detected occasionally in CF terminals at P14 (Fig. 8C), whereas the labeling was rare at the adult stage (Fig. $8 F$ ). Most of the CB1 labeling was seen along the cell membrane. When the labeling density was calculated from synaptic profiles with synaptic junctions, the density was in the order of inhibitory terminals $>$ PF terminals $>$ CF terminals at both $\mathrm{P} 14$ and adult (Fig. $8 G, H)$. Importantly, the density in PF terminals at $\mathrm{P} 14$ and in adult was significantly higher than the background level, which was estimated in PC shaft dendrites taken from the same sections (Fig. $8 G, H$ ). Furthermore, the density in PF terminals in

adult was higher than the noise level, which was estimated from immunogold particle density in PF terminals of CB1 knock-out mice (Fig. $8 H$ ). The density in CF terminals was higher at P14 than in adult (Fig. 8G,H). The scores at these two developmental stages were apparently higher than the background level of PC shaft dendrites and the noise level of CB1 knock-out mice. However, the differences were not statistically significant at both P14 and adult. In any types of PC synapses the junctional terminal membranes and postsynaptic membranes, including dendrites and spines, were hardly labeled.

Although the CB1 labeling density in PF terminals was five to six times less than that in inhibitory terminals, heavy CB1 label-
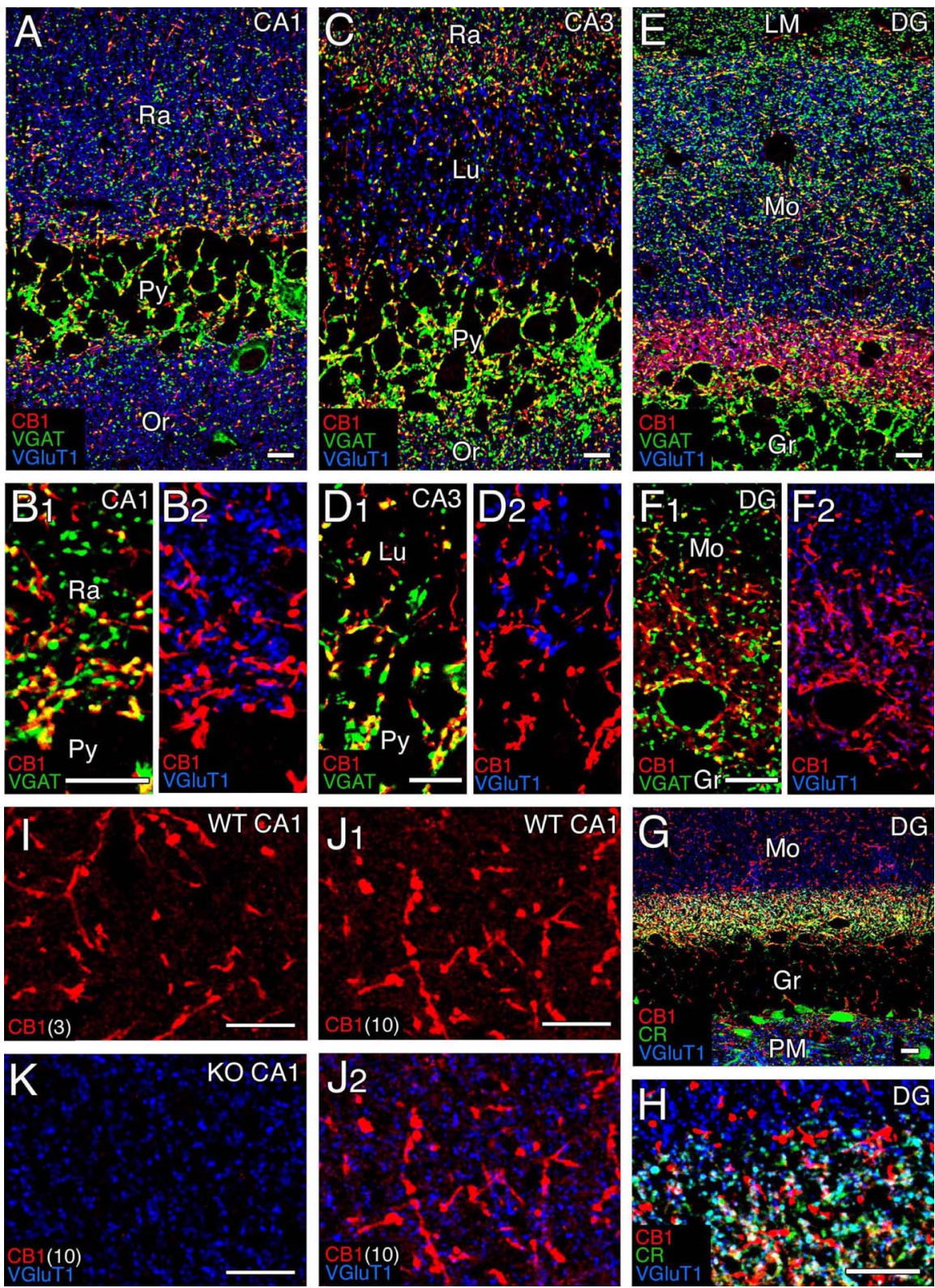
cence for CB1 (red), VGAT (green), and VGluT1 (blue) in the CA1 $(\boldsymbol{A}, \boldsymbol{B}), C \mathrm{C} 3(\boldsymbol{C}, \boldsymbol{D})$, and dentate gyrus (DG; $\boldsymbol{E}, \boldsymbol{F}) . \boldsymbol{G}, \boldsymbol{H}$, Immunofluorescence for CB1 (red), calretinin (green), and VGluT1 (blue) in the DG. Note calretinin-positive neurons in the polymorphic antibody concentration. Shown are images from wild-type $(\boldsymbol{I}, \boldsymbol{J})$ and CB1 knock-out $(\boldsymbol{K})$ hippocampi with antibody concentrations of $3 \mu \mathrm{g} / \mathrm{ml}(\boldsymbol{I})$ and $10 \mu \mathrm{g} / \mathrm{ml}(\boldsymbol{J}, \boldsymbol{K})$. Gr, Granule cell layer; LM, stratum lacunosum-moleculare; Lu, stratum lucidum; 0 r, stratum oriens; Py, pyramidal cell layer; Ra, stratum radiatum. Scale bars, $10 \mu \mathrm{m}$.

ing often was encountered in PF profiles lacking synaptic junctions (data not shown). Together with intense CB1 immunofluorescence in the molecular layer, this result suggests the presence of CB1 at a high density in extrasynaptic portions of PFs. To check this possibility, we cut transverse cerebellar sections and examined the labeling of PFs along their longitudinal axes (Fig. 9). A heavy deposit of immunogold was observed in the perisynaptic portion of PFs at P14 and adult (Fig. 9A,B). We quantified the labeling density as the number of particles per micrometer of axonal membrane at synaptic, perisynaptic $(<500 \mathrm{~nm}$ from the edge of synaptic junction), and extrasynaptic regions ( $>500 \mathrm{~nm}$ ) (Fig. 9C). The labeling density of PFs was in the order of perisynaptic $>$ extrasynaptic $>$ synaptic at P14 and adult (Fig. 9D,E). In 

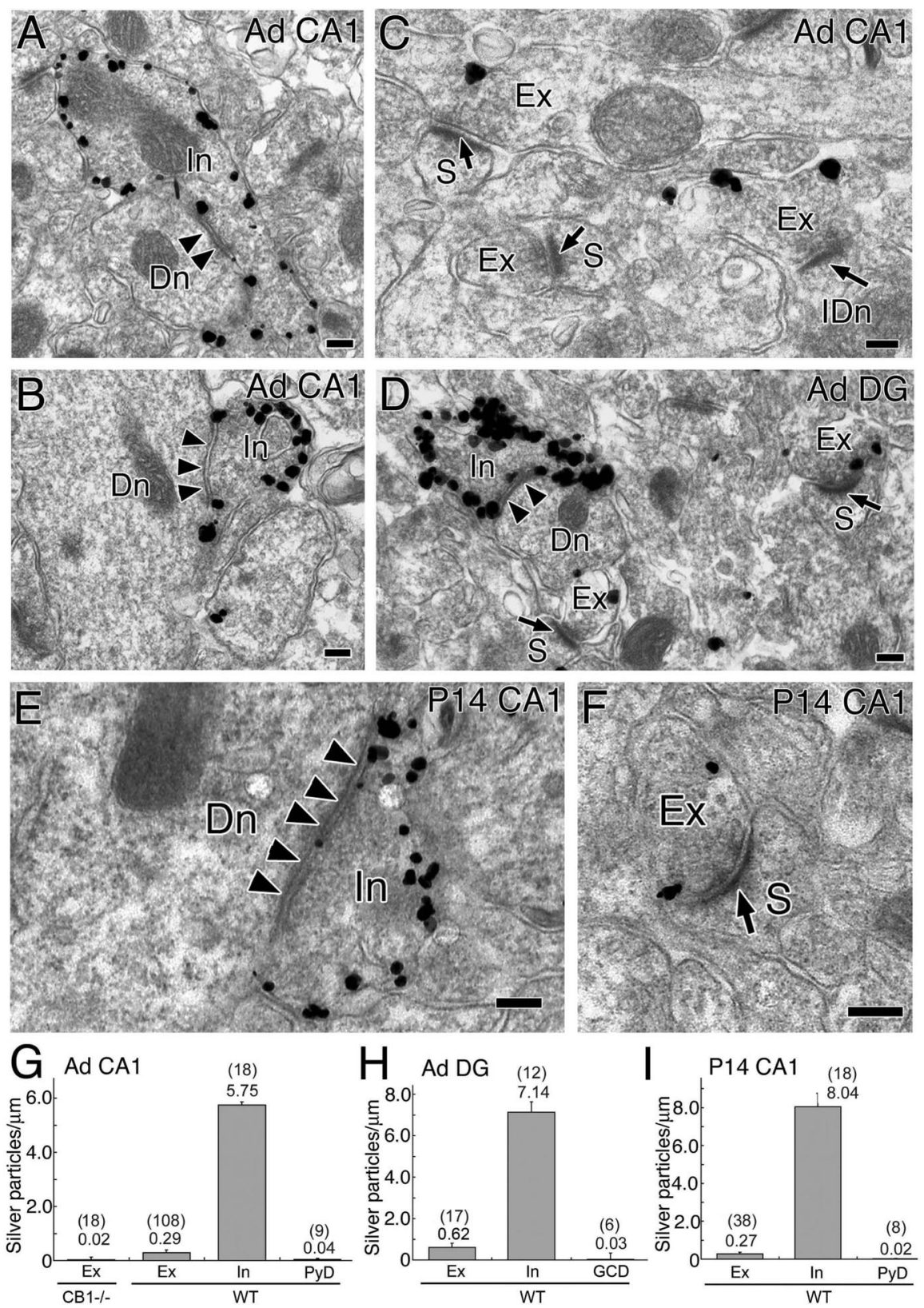

Figure 6. Immunoelectron microscopy showing subcellular and synaptic localization of $\mathrm{CB} 1$ in the hippocampus at adult $(\boldsymbol{A}-\boldsymbol{D}$, $\boldsymbol{G}, \boldsymbol{H})$ and $\mathrm{P} 14(\boldsymbol{E}, \boldsymbol{F}, \boldsymbol{I}) \cdot \boldsymbol{A}-\boldsymbol{F}$, Preembedding silver-enhanced immunogold for $(\mathrm{B} 1$ in the stratum radiatum of the hippocampal $\mathrm{CA} 1$ region $(\boldsymbol{A}-\boldsymbol{C}, \boldsymbol{E}, \boldsymbol{F})$ and in the innermost molecular layer of the dentate gyrus $(\boldsymbol{D})$. Arrowheads and arrows indicate symmetrical and asymmetrical synapses, respectively. $\mathbf{G}-\mathbf{I}$, Summary bar graphs showing the number of silver particles per $1 \mu \mathrm{m}$ of plasma membrane in excitatory terminals (Ex), inhibitory terminals (In), pyramidal cell dendrite (PyD), and granule cell dendrites (GCD) in the hippocampal $C A 1(G, I)$ and dentate gyrus (DG; $\boldsymbol{H})$. In wild-type mice (WT) the densities in excitatory and inhibitory terminals were significantly higher $(p<0.05)$ than the background level of PyD or $\operatorname{GCD}(\boldsymbol{G}, \boldsymbol{H}, \boldsymbol{I})$. Furthermore, the density in excitatory terminals in adult wild-type mice was significantly higher $(p<0.01)$ than the noise level, which was estimated from immunogold particle density in excitatory terminals of $(B 1$ knock-out mice $(G)$. The numbers in and out of parentheses on the top of each column $(\mathbf{G}-\boldsymbol{I})$ indicate the sample size and the mean density of silver particles, respectively. Dn, Dendrite; IDn, interneuronal dendrite; $S$, dendritic spine. Scale bars, $100 \mathrm{~nm}$. Error bars indicate the mean \pm SEM.

particular, accumulation in the perisynaptic region was more prominent at adult than at P14.

Thus in the cerebellar cortex CB1 is highly expressed in inhibitory terminals and the perisynaptic region of PFs, whereas CB1 expression is low or just around the detection threshold in $\mathrm{CF}$ terminals. Higher density in extrasynaptic labeling at P14 than in adult additionally suggests that the degree of perisynaptic accumulation of CB1 increases with cerebellar maturation.

\section{Discussion}

In the present study we have used CB1 knock-out mice and demonstrated clearly that CB1 mediates the cannabinoiddependent suppression of excitatory synapses in the hippocampus and cerebellum. Previous studies suggested a predominant contribution of a cannabinoid receptor other than CB1 (so-called CB3) at hippocampal excitatory synapses by using CB1 knock-out mice (Hajos et al., 2001) and AM251 (Hajos and Freund, 2002a). However, we could not detect any contribution of CB3 at any age of the mice that were tested. Reasons for this discrepancy are not clear. Our present data on hippocampal slices are consistent with the studies that used cultured hippocampal neurons from wild-type and CB1 knockout mice (Ohno-Shosaku et al., 2002b; Straiker and Mackie, 2005) and also with recent studies in which AM251 was applied to rat hippocampal slices (Lees and Dougalis, 2004; Slanina and Schweitzer, 2005).

Very recently, Hoffman et al. (2005) reported that WIN55,212-2 had no suppressive effect on EPSCs at CA3 $\rightarrow$ CA1 synapses in C57BL/6 mice, which contradicts our present results (Hoffman et al., 2005). To pursue possible reasons for this discrepancy, we examined C57BL/6 mice from Charles River Laboratories, the same source as Hoffman et al. (2005). We found that WIN55,212-2 $(2 \mu \mathrm{M})$ readily suppressed CA3/CA1 EPSCs to $25.2 \pm 4.4 \%$ $(n=8)$ of control, which was reversed to $93.2 \pm 5.4 \%(n=8)$ by the subsequent application of AM251 ( $2 \mu \mathrm{M})$. Thus reasons for the discrepancy between the results of our present study and those of Hoffman et al. (2005) are not clear.

As to cerebellar excitatory synapses, types of cannabinoid receptor have not been determined electrophysiologically by using CB1 knock-out mice. The present study provides the first evidence that the cannabinoid-dependent suppression at PF and CF synapses is CB1-dependent.

Electrophysiological studies using CB1 knock-out mice have determined the type of presynaptic cannabinoid receptor at excitatory synapses in several brain regions. The CB1 dependence of cannabinoidinduced suppression of EPSCs (or EPSPs) has been reported in the striatum (Gerdeman et al., 2002), olfactory cortex (Whalley et al., 2004), nucleus accumbens (Robbe et al., 2002), lateral amygdala (Azad et al., 2003), and ventral tegmental area (Melis et al., 2004). The present study demonstrates that CB1 mediates cannabinoid-induced presynaptic suppression of excitatory transmission in the hippocampus and cerebellum. Thus most of the electrophysiological studies support the 
idea that the $\mathrm{CB} 1$ is the major cannabinoid receptor responsible for cannabinoiddependent presynaptic modulation at not only inhibitory but also excitatory synapses in the brain.

Immunohistochemical studies with antibodies directed against CB1 have supported the presence of presynaptic CB1 at some excitatory synapses, including cerebellar PF synapses (Egertova and Elphick, 2000) and the excitatory synapses in the supraoptic nucleus (Hirasawa et al., 2004). However, CB1-positive signals have not been detected at cannabinoid-sensitive excitatory synapses in most of other brain regions such as the hippocampus (Katona et al., 1999; Hajos et al., 2000), amygdala (Katona et al., 2001), and somatosensory cortex (Bodor et al., 2005). As for the hippocampus, our immunohistochemical data at the light microscopic level are apparently consistent with the previous reports. The CB1 immunoreactivity was detected on inhibitory (VGAT-positive) terminals but was absent on excitatory (VGluT1-positive) synapses in CA1/CA3 areas of the hippocampus when CB1 antibody was used at $1 \mu \mathrm{g} / \mathrm{ml}$. By raising the antibody concentration in immunofluorescence and also by adopting highly sensitive preembedding immunogold electron microscopy, we could detect CB1 on these excitatory terminals. The signal levels on these terminals were much lower than those on inhibitory terminals but significantly higher than the background level. Thus it is evident that CB1 molecules exist on hippocampal excitatory terminals. We additionally found that terminals of mossy cells in the dentate gyrus exhibited relatively dense labeling of CB1. The functional significance of CB1 at mossy cell terminals remains to be elucidated.

Electrophysiological, immunocytochemical, and in situ hybridization studies all support a low expression level of CB1 at hippocampal excitatory terminals. We reported previously that the cannabinoid sensitivity of excitatory transmission is much lower than that of the inhibitory one in cultured hippocampal neurons (Ohno-Shosaku et al., 2002b). When the cannabinoid agonist WIN55,212-2 was applied exogenously, the concentrations of WIN55,212-2 required for 50\% suppression were $\sim 2$ and $\sim 60 \mathrm{~nm}$ for inhibitory and excitatory synaptic responses, respectively. The difference in the sensitivity to endocannabinoids released by postsynaptic depolarization is also in line with the difference in cannabinoid sensitivity between excitatory and inhibitory synaptic responses. The duration of depolarization required for suppression of excitatory transmission was longer than that of inhibitory transmission (Ohno-Shosaku et al., 2002b). These electrophysiological data for low cannabinoid sensitivity of hippocampal excitatory synapses are consistent with the present immunohistochemical data. The electron microscopic data show the 20 - to 30 -fold difference in the density of metal particles
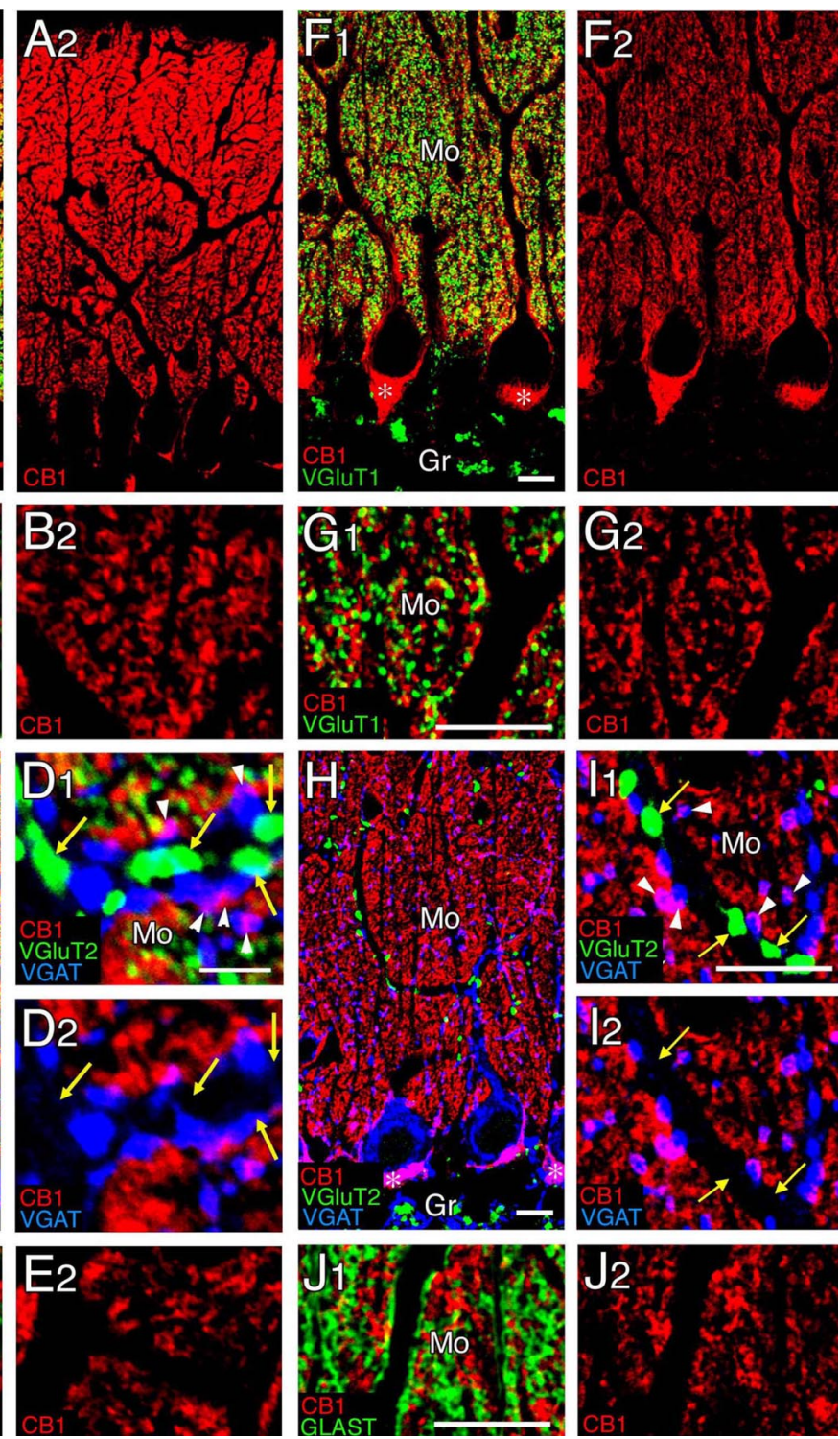

Figure 7. Confocal laser-scanning microscopy showing distribution of $C B 1$ in the cerebellar cortex at P14 $(\boldsymbol{A}-\boldsymbol{E})$ and adult (F-J). A, B, F, G, Immunofluorescence for CB1 (red) and VGluT1 (green). C, $\boldsymbol{D}, \boldsymbol{H}, \boldsymbol{I}$, Immunofluorescence for CB1 (red), VGluT2 indicate VGAT-labeled inhibitory terminals carrying CB1 labeling. Asterisks in $\boldsymbol{F}_{\boldsymbol{1}}$ and $\boldsymbol{H}$ indicate the pinceau formation. $\boldsymbol{E}, \boldsymbol{J}$, Immunofluorescence for CB1 (red) and GLAST (green). Gr, Granular layer; Mo, molecular layer. Scale bars, $10 \mu \mathrm{m}$.

between inhibitory and excitatory terminals at P14. These results are also consistent with those from the in situ hybridization study that hippocampal pyramidal neurons contain only low levels of mRNA for CB1 (Marsicano and Lutz, 1999).

As for the cerebellar cortex, however, there is an apparent quantitative discrepancy between electrophysiological and immunohistochemical data. It is well known that inhibitory synaptic inputs and CF- and PF-derived excitatory inputs to PCs are all sensitive to cannabinoids and undergo depolarization-induced retrograde suppression mediated by endocannabinoids (Kreitzer and Regehr, 2001a,b; Maejima et al., 2001; Diana et al., 2002; Yoshida et al., 2002). The cannabinoid sensitivity at inhibitory and $\mathrm{CF} / \mathrm{PF}$ excitatory synapses was estimated by measuring the response to endocannabinoids released by postsynaptic depolarization (Brenowitz and Regehr, 2003). This study shows that the peak concentration of $\mathrm{Ca}^{2+}$ transient required for retrograde synaptic suppression is the same for all of these inputs, suggesting 

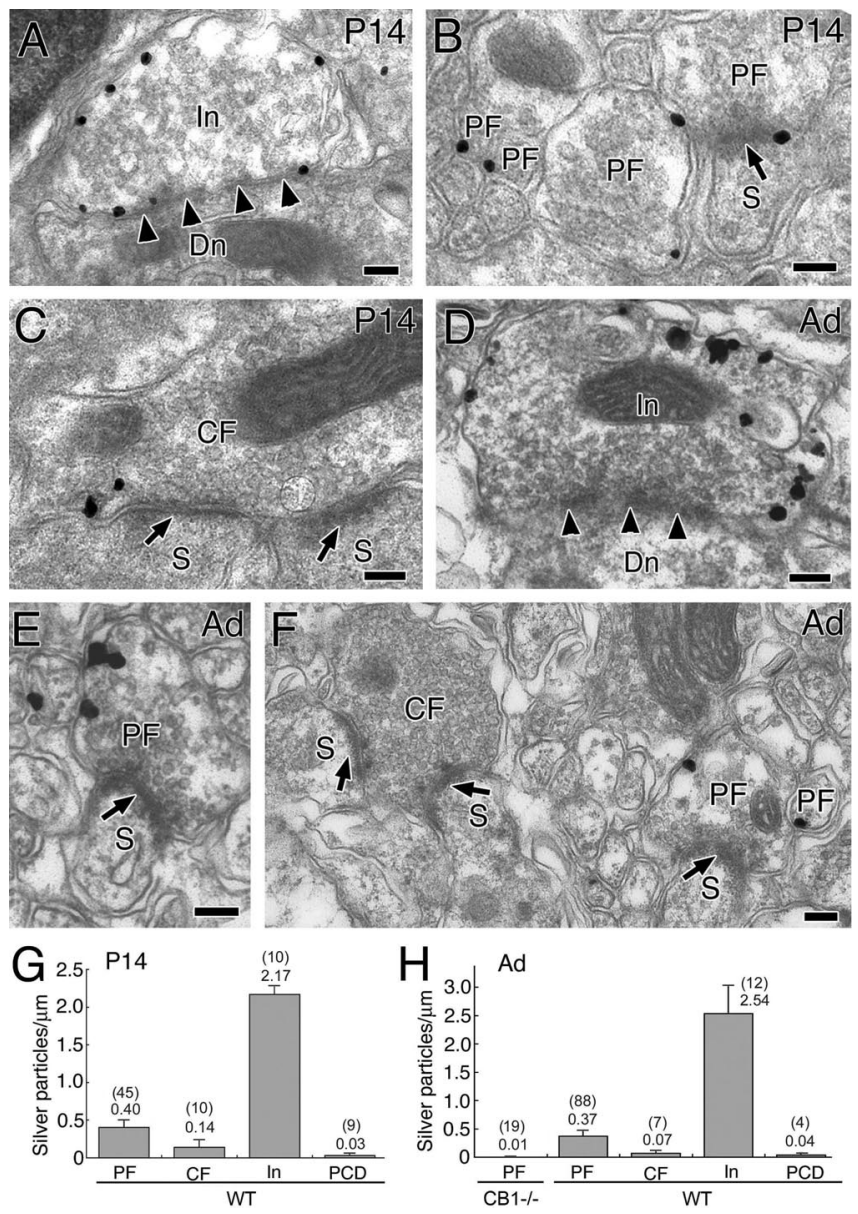

Figure 8. Immunoelectron microscopy showing localization of $\mathrm{CB} 1$ in the cerebellar molecular layer at P14 $(\boldsymbol{A}-\boldsymbol{C}, \boldsymbol{G})$ and adult $(\boldsymbol{D}-\boldsymbol{F}, \boldsymbol{H})$. $\boldsymbol{A}-\boldsymbol{F}$, Preembedding silver-enhanced immunogold for $C B 1$ in the cerebellar cortex, using parasagittal cerebellar sections. Arrowheads and arrows indicate symmetrical and asymmetrical synapses, respectively. $\boldsymbol{G}, \boldsymbol{H}$, Summary bar graphs showing the number of silver particles per $1 \mu \mathrm{m}$ of plasma membrane in $\mathrm{PF}$, $C F$, inhibitory terminals (In), and PC dendrites (PCD). In wild-type mice (WT), the densities in PF and In were significantly higher $(p<0.05)$ than the background level of $\operatorname{PCD}(\boldsymbol{G}, \boldsymbol{H})$. Furthermore, the density in PF in adult wild-type mice was significantly higher $(p<0.01)$ than the noise level, which was estimated from immunogold particle density in PF terminals of CB1 knock-out mice $(\boldsymbol{H})$. In contrast, the immunogold particle density in $(F$ was not significantly higher than the background level at P14 and in adult $(\boldsymbol{G}, \boldsymbol{H})$, or the noise level in adult $(\boldsymbol{H})$. The numbers in and out of parentheses on the top of each column $(\boldsymbol{G}, \boldsymbol{H})$ indicate the sample size and the mean density of silver particles. Scale bars, $100 \mathrm{~nm}$. Error bars indicate the mean \pm SEM.

that these terminals have similar cannabinoid sensitivity. In contrast, our immunohistochemical data show a large difference in the density of the CB1-positive signal among these three types of terminals. One possible explanation is that the intracellular signaling pathway from $\mathrm{CB} 1$ activation to transmitter release might be different in different types of terminals. CB1 activation might induce suppression of transmitter release more effectively at excitatory terminals than at inhibitory ones. Another possibility is that the difference in cannabinoid sensitivity exists as in the hippocampus, but it might be obscured by the difference in distance between the synapse and the site of endocannabinoid release. We also could not exclude the possibility that the binding of our C-terminal antibodies to CB1 might be occluded at excitatory terminals, for example, via phosphorylation of CB1 or its interaction with some other molecules.

Our electron microscopic data have revealed that the $\mathrm{CB} 1$ is densely distributed in the perisynaptic region of PFs, as compared
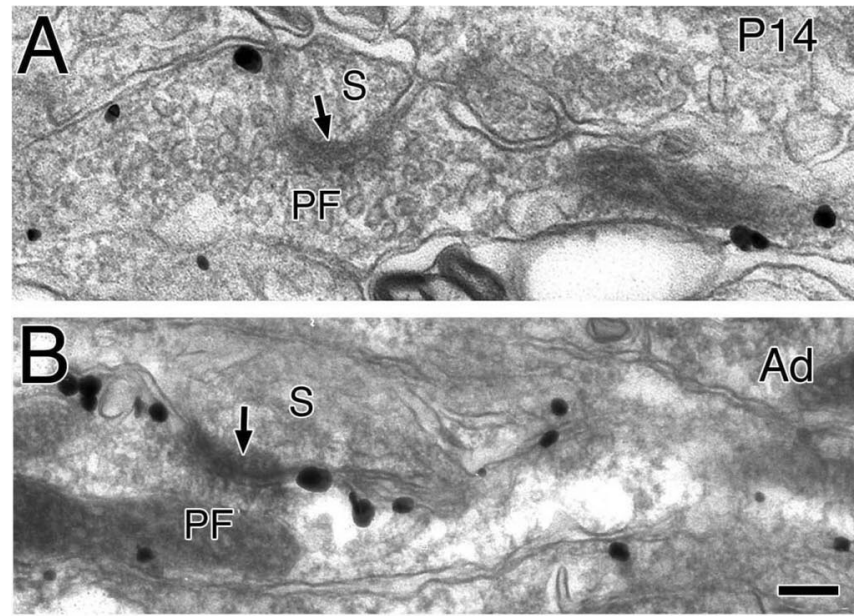

C
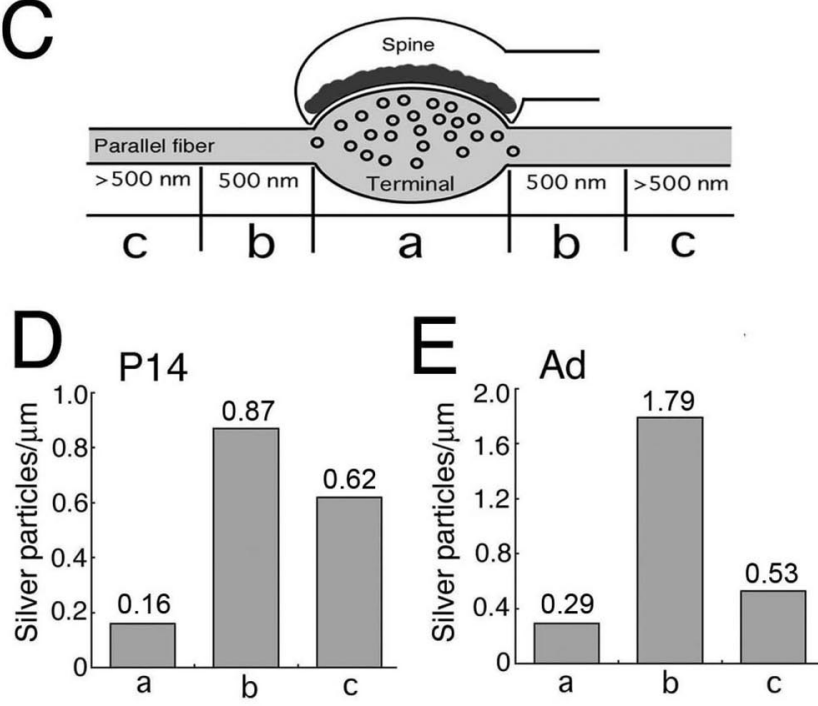

Figure 9. Preferential perisynaptic localization of $\mathrm{CB} 1$ along PFs at P14 $(\boldsymbol{A}, \boldsymbol{D})$ and adult ( $\boldsymbol{B}$ E). Shown is $(B 1$ distribution along longitudinally sectioned PFs at P14 (A) and adult ( $B$ ). Arrows indicate asymmetrical synaptic junction with $P($ spines (S). C, Scheme for illustrating segmented measurement of synaptic (a), perisynaptic (b), and extrasynaptic (c) distributions of CB1 along PFs. D, E, Summary bar graphs showing the density of CB1 at synaptic (a), perisynaptic (b), and extrasynaptic (c) regions at P14 (D) and adult (E). The number on the top of each column $(\boldsymbol{D}, \boldsymbol{E})$ indicates the mean density of silver particles. Scale bar, $100 \mathrm{~nm}$.

with synaptic and extrasynaptic regions. What is the advantage of this perisynaptic location of $\mathrm{CB} 1$ at $\mathrm{PF}$ axon terminals? In the cerebellum a physiological range of $\mathrm{PF}$ activity triggers the endocannabinoid release, resulting in a suppression of PF-EPSCs (Brenowitz and Regehr, 2005; Maejima et al., 2005). This activityinduced endocannabinoid release requires the postsynaptic activation of type $1 \mathrm{mGluR}$ (mGluR1) (Brenowitz and Regehr, 2005; Maejima et al., 2005). It is proposed that the mGluR1 activation drives phospholipase C $\beta 4$ (PLC $\beta 4)$ and yields diacylglycerol (DAG), which then is converted to the endocannabinoid 2 -arachidonoylglycerol (2-AG) by the enzymatic activity of DAG lipase (Maejima et al., 2005). Interestingly, mGluR1 and PLC $\beta 4$ both are concentrated in the perisynaptic site of postsynaptic membrane (Lujan et al., 1997; Nakamura et al., 2004). If the perisynaptic $\mathrm{CB} 1$ at $\mathrm{PF}$ axon terminals can detect endocannabinoids more effectively than synaptic and extrasynaptic receptors because of its closer proximity to the postsynaptic release site, the heterogeneous distribution of CB1 along PFs that has been observed here may be functionally relevant. 
Biochemical studies suggest the presence of non-CB1 type cannabinoid receptor(s) on excitatory terminals. Via the monitoring of $\left[{ }^{3} \mathrm{H}\right]$ glutamate release from hippocampal (Kofalvi et al., 2003) and striatal (Kofalvi et al., 2005) synaptosomes evoked by high- $\mathrm{K}^{+}$depolarization, these studies report that suppression of glutamate release by a high dose of WIN55,212-2 (20 $\mu \mathrm{M})$ persisted in CB1 knock-out mice. The cannabinoid receptor involved in this suppression is different from CB3, because it is not antagonized by SR141716A, an antagonist for both CB1 and CB3 (Hajos et al., 2001; Hajos and Freund, 2002a). In these synaptosome preparations it also was found that cannabinoid antagonists (SR141716A and AM251) by themselves attenuated the glutamate release (Kofalvi et al., 2003, 2005). A possible interpretation of these results is that the glutamate release is influenced by a high dose of WIN55,212-2 via non-CB1, non-CB3 cannabinoid receptors that can be activated by both cannabinoid agonists and antagonists. Alternatively, the suppression might be induced by some nonspecific actions of cannabinoids. Nevertheless, this non-CB1-, non-CB3-mediated modulation is considered to have little physiological significance because of its low sensitivity to cannabinoids. Thus under physiological conditions the CB1 should be the predominant receptor involved in cannabinoiddependent synaptic modulation at both inhibitory and excitatory synapses in the brain.

\section{References}

Alger BE (2002) Retrograde signaling in the regulation of synaptic transmission: focus on endocannabinoids. Prog Neurobiol 68:247-286.

Azad SC, Eder M, Marsicano G, Lutz B, Zieglgansberger W, Rammes G (2003) Activation of the cannabinoid receptor type 1 decreases glutamatergic and GABAergic synaptic transmission in the lateral amygdala of the mouse. Learn Mem 10:116-128.

Begg M, Pacher P, Batkai S, Osei-Hyiaman D, Offertaler L, Mo FM, Liu J, Kunos G (2005) Evidence for novel cannabinoid receptors. Pharmacol Ther 106:133-145.

Bodor AL, Katona I, Nyiri G, Mackie K, Ledent C, Hajos N, Freund TF (2005) Endocannabinoid signaling in rat somatosensory cortex: laminar differences and involvement of specific interneuron types. J Neurosci 25:6845-6856.

Brenowitz SD, Regehr WG (2003) Calcium dependence of retrograde inhibition by endocannabinoids at synapses onto Purkinje cells. J Neurosci 23:6373-6384.

Brenowitz SD, Regehr WG (2005) Associative short-term synaptic plasticity mediated by endocannabinoids. Neuron 45:419-431.

Diana MA, Levenes C, Mackie K, Marty A (2002) Short-term retrograde inhibition of GABAergic synaptic currents in rat Purkinje cells is mediated by endogenous cannabinoids. J Neurosci 22:200-208.

Egertova M, Elphick MR (2000) Localisation of cannabinoid receptors in the rat brain using antibodies to the intracellular C-terminal tail of $\mathrm{CB}$. J Comp Neurol 422:159-171.

Freund TF, Katona I, Piomelli D (2003) Role of endogenous cannabinoids in synaptic signaling. Physiol Rev 83:1017-1066.

Fukudome Y, Ohno-Shosaku T, Matsui M, Omori Y, Fukaya M, Tsubokawa H, Taketo MM, Watanabe M, Manabe T, Kano M (2004) Two distinct classes of muscarinic action on hippocampal inhibitory synapses: $\mathrm{M}_{2}-$ mediated direct suppression and $\mathrm{M}_{1} / \mathrm{M}_{3}$-mediated indirect suppression through endocannabinoid signaling. Eur J Neurosci 19:2682-2692.

Gerdeman GL, Lovinger DM (2003) Emerging roles for endocannabinoids in long-term synaptic plasticity. Br J Pharmacol 140:781-789.

Gerdeman GL, Ronesi J, Lovinger DM (2002) Postsynaptic endocannabinoid release is critical to long-term depression in the striatum. Nat Neurosci 5:446-451.

Hajos N, Freund TF (2002a) Pharmacological separation of cannabinoidsensitive receptors on hippocampal excitatory and inhibitory fibers. Neuropharmacology 43:503-510.

Hajos N, Freund TF (2002b) Distinct cannabinoid-sensitive receptors regulate hippocampal excitation and inhibition. Chem Phys Lipids 121:73-82.

Hajos N, Katona I, Naiem SS, Mackie K, Ledent C, Mody I, Freund TF (2000)
Cannabinoids inhibit hippocampal GABAergic transmission and network oscillations. Eur J Neurosci 12:3239-3249.

Hajos N, Ledent C, Freund TF (2001) Novel cannabinoid-sensitive receptor mediates inhibition of glutamatergic synaptic transmission in the hippocampus. Neuroscience 106:1-4.

Hashimotodani Y, Ohno-Shosaku T, Tsubokawa H, Ogata H, Emoto K, Maejima T, Araishi K, Shin HS, Kano M (2005) Phospholipase C $\beta$ serves as a coincidence detector through its $\mathrm{Ca}^{2+}$ dependency for triggering retrograde endocannabinoid signal. Neuron 45:257-268.

Hirasawa M, Schwab Y, Natah S, Hillard CJ, Mackie K, Sharkey KA, Pittman QJ (2004) Dendritically released transmitters cooperate via autocrine and retrograde actions to inhibit afferent excitation in rat brain. J Physiol (Lond) 559:611-624.

Hoffman AF, Macgill AM, Smith D, Oz M, Lupica CR (2005) Species and strain differences in the expression of a novel glutamate-modulating cannabinoid receptor in the rodent hippocampus. Eur J Neurosci 22:2387-2391.

Howlett AC, Barth F, Bonner TI, Cabral G, Casellas P, Devane WA, Felder CC, Herkenham M, Mackie K, Martin BR, Mechoulam R, Pertwee RG (2002) International Union of Pharmacology. XXVII. Classification of cannabinoid receptors. Pharmacol Rev 54:161-202.

Ito M (1984) The cerebellum and neural control. New York: Raven.

Kano M, Hashimoto K, Chen C, Abeliovich A, Aiba A, Kurihara H, Watanabe $\mathrm{M}$, Inoue $\mathrm{Y}$, Tonegawa S (1995) Impaired synapse elimination during cerebellar development in PKC $\gamma$ mutant mice. Cell 83:1223-1231.

Kano M, Ohno-Shosaku T, Maejima T, Yoshida T, Hashimoto K (2004) Retrograde modulation of synaptic transmission mediated by endogenous cannabinoids. Curr Neuropharmacol 2:49-57.

Katona I, Sperlagh B, Sik A, KŁfalvi A, Vizi ES, Mackie K, Freund TF (1999) Presynaptically located $\mathrm{CB} 1$ cannabinoid receptors regulate GABA release from axon terminals of specific hippocampal interneurons. J Neurosci 19:4544-4558.

Katona I, Rancz EA, Acsady L, Ledent C, Mackie K, Hajos N, Freund TF (2001) Distribution of CB1 cannabinoid receptors in the amygdala and their role in the control of GABAergic transmission. J Neurosci 21:9506-9518.

Kofalvi A, Vizi ES, Ledent C, Sperlagh B (2003) Cannabinoids inhibit the release of $\left[{ }^{3} \mathrm{H}\right]$ glutamate from rodent hippocampal synaptosomes via a novel CB1 receptor-independent action. Eur J Neurosci 18:1973-1978.

Kofalvi A, Rodrigues RJ, Ledent C, Mackie K, Vizi ES, Cunha RA, Sperlagh B (2005) Involvement of cannabinoid receptors in the regulation of neurotransmitter release in the rodent striatum: a combined immunochemical and pharmacological analysis. J Neurosci 25:2874-2884.

Kreitzer AC, Regehr WG (2001a) Cerebellar depolarization-induced suppression of inhibition is mediated by endogenous cannabinoids. J Neurosci $21: R C 174(1-5)$

Kreitzer AC, Regehr WG (2001b) Retrograde inhibition of presynaptic calcium influx by endogenous cannabinoids at excitatory synapses onto Purkinje cells. Neuron 29:717-727.

Lees G, Dougalis A (2004) Differential effects of the sleep-inducing lipid oleamide and cannabinoids on the induction of long-term potentiation in the CA1 neurons of the rat hippocampus in vitro. Brain Res 997:1-14.

Lujan R, Roberts JDB, Shigemoto R, Ohishi H, Somogyi P (1997) Differential plasma membrane distribution of metabotropic glutamate receptor mGluR1 $\alpha$, mGluR2, and mGluR5, relative to neurotransmitter release sites. J Chem Neuroanat 13:219-241.

Maejima T, Hashimoto K, Yoshida T, Aiba A, Kano M (2001) Presynaptic inhibition caused by retrograde signal from metabotropic glutamate to cannabinoid receptors. Neuron 31:463-475.

Maejima T, Oka S, Hashimotodani Y, Ohno-Shosaku T, Aiba A, Wu D, Waku K, Sugiura T, Kano M (2005) Synaptically driven endocannabinoid release requires $\mathrm{Ca}^{2+}$-assisted metabotropic glutamate receptor subtype 1 to phospholipase $\mathrm{C} \beta 4$ signaling cascade in the cerebellum. J Neurosci 25:6826-6835.

Marsicano G, Lutz B (1999) Expression of the cannabinoid receptor CB1 in distinct neuronal subpopulations in the adult mouse forebrain. Eur J Neurosci 11:4213-4225.

Matsuda LA, Lolait SJ, Brownstein MJ, Young AC, Bonner TI (1990) Structure of a cannabinoid receptor and functional expression of the cloned cDNA. Nature 346:561-564.

Matyas F, Freund TF, Gulyas AI (2004) Immunocytochemically defined in- 
terneuron populations in the hippocampus of mouse strains used in transgenic technology. Hippocampus 14:460-481.

Melis M, Perra S, Muntoni AL, Pillolla G, Lutz B, Marsicano G, Di Marzo V, Gessa GL, Pistis M (2004) Prefrontal cortex stimulation induces 2-arachidonoyl-glycerol-mediated suppression of excitation in dopamine neurons. J Neurosci 24:10707-10715.

Miyazaki T, Fukaya M, Shimizu H, Watanabe M (2003) Subtype switching of vesicular glutamate transporters at parallel fibre-Purkinje cell synapses in developing mouse cerebellum. Eur J Neurosci 17:2563-2572.

Munro S, Thomas KL, Abu-Shaar M (1993) Molecular characterization of a peripheral receptor for cannabinoids. Nature 365:61-65.

Nakamura M, Sato K, Fukaya M, Araishi K, Aiba A, Kano M, Watanabe M (2004) Signaling complex formation of phospholipase C $\beta 4$ with metabotropic glutamate receptor type $1 \alpha$ and 1,4,5-trisphosphate receptor at the perisynapse and endoplasmic reticulum in the mouse brain. Eur J Neurosci 20:2929-2944.

Ohno-Shosaku T, Shosaku J, Tsubokawa H, Kano M (2002a) Cooperative endocannabinoid production by neuronal depolarization and group I metabotropic glutamate receptor activation. Eur J Neurosci 15:953-961.

Ohno-Shosaku T, Tsubokawa H, Mizushima I, Yoneda N, Zimmer A, Kano M (2002b) Presynaptic cannabinoid sensitivity is a major determinant of depolarization-induced retrograde suppression at hippocampal synapses. J Neurosci 22:3864-3872.

Ohno-Shosaku T, Hashimotodani Y, Maejima T, Kano M (2005) Calcium signaling and synaptic modulation: regulation of endocannabinoidmediated synaptic modulation by calcium. Cell Calcium 38:369-374.

Robbe D, Kopf M, Remaury A, Bockaert J, Manzoni OJ (2002) Endogenous cannabinoids mediate long-term synaptic depression in the nucleus accumbens. Proc Natl Acad Sci USA 99:8384-8388.

Shibata T, Yamada K, Watanabe M, Ikenaka K, Wada K, Tanaka K, Inoue Y
(1997) Glutamate transporter GLAST is expressed in the radial glia-astrocyte lineage of developing mouse spinal cord. J Neurosci 17:9212-9219.

Slanina KA, Schweitzer P (2005) Inhibition of cyclooxygenase-2 elicits a CB1-mediated decrease of excitatory transmission in rat CA1 hippocampus. Neuropharmacology 49:653-659.

Straiker A, Mackie K (2005) Depolarisation-induced suppression of excitation in murine autaptic hippocampal neurons. J Physiol (Lond) 569:501-517.

Tsubokawa H, Offermanns S, Simon M, Kano M (2000) Calciumdependent persistent facilitation of spike backpropagation in the CA1 pyramidal neurons. J Neurosci 20:4878-4884.

Varma N, Carlson GC, Ledent C, Alger BE (2001) Metabotropic glutamate receptors drive the endocannabinoid system in hippocampus. J Neurosci 21:RC188(1-5).

Whalley BJ, Wilkinson JD, Williamson EM, Constanti A (2004) A novel component of cannabis extract potentiates excitatory synaptic transmission in rat olfactory cortex in vitro. Neurosci Lett 365:58-63.

Wiley JL, Martin BR (2002) Cannabinoid pharmacology: implications for additional cannabinoid receptor subtypes. Chem Phys Lipids 121:57-63.

Wilson RI, Kunos G, Nicoll RA (2001) Presynaptic specificity of endocannabinoid signaling in the hippocampus. Neuron 31:453-462.

Yoshida T, Hashimoto K, Zimmer A, Maejima T, Araishi K, Kano M (2002) The cannabinoid $\mathrm{CB} 1$ receptor mediates retrograde signals for depolarization-induced suppression of inhibition in cerebellar Purkinje cells. J Neurosci 22:1690-1697.

Zimmer A, Zimmer AM, Hohmann AG, Herkenham M, Bonner TI (1999) Increased mortality, hypoactivity, and hypoalgesia in cannabinoid CB1 receptor knock-out mice. Proc Natl Acad Sci USA 96:5780-5785. 